\title{
Native and Complexed IGF-1: Biodistribution and Pharmacokinetics in Infantile Neuronal Ceroid Lipofuscinosis
}

\author{
Tuulia Huhtala, ${ }^{1,2}$ Jussi Rytkönen, ${ }^{2,3}$ Anu Jalanko, ${ }^{4}$ Martti Kaasalainen, ${ }^{5}$ \\ Jarno Salonen, ${ }^{5}$ Raili Riikonen, ${ }^{6}$ and Ale Närvänen ${ }^{2,3}$ \\ ${ }^{1}$ A.I. Virtanen Institute, University of Eastern Finland, 70211 Kuopio, Finland \\ ${ }^{2}$ Biocenter Kuopio, University of Eastern Finland, 70211 Kuopio, Finland \\ ${ }^{3}$ School of Pharmacy, University of Eastern Finland, 70211 Kuopio, Finland \\ ${ }^{4}$ National Institute for Health and Welfare, Public Health Genomics Unit, Biomedicum Helsinki, Haartmaninkatu 8, \\ 00290 Helsinki, Finland \\ ${ }^{5}$ Department of Physics and Astronomy, University of Turku, 20014 Turku, Finland \\ ${ }^{6}$ Department of Pediatrics, Kuopio University Hospital, 70211 Kuopio, Finland
}

Correspondence should be addressed to Ale Närvänen, ale.narvanen@uef.fi

Received 22 February 2012; Revised 11 April 2012; Accepted 18 April 2012

Academic Editor: Jia You Fang

Copyright (๑) 2012 Tuulia Huhtala et al. This is an open access article distributed under the Creative Commons Attribution License, which permits unrestricted use, distribution, and reproduction in any medium, provided the original work is properly cited.

Infantile neuronal ceroid lipofuscinosis (INCL) is a severe neurodegenerative disorder of childhood characterized by selective death of cortical neurons. Insulin-like growth factor 1 (IGF-1) is important in embryonic development and is considered as a potential therapeutic agent for several disorders of peripheral and central nervous systems. In circulation IGF-1 is mainly bound to its carrier protein IGFBP-3. As a therapeutic agent IGF-1 has shown to be more active as free than complexed form. However, this may cause side effects during the prolonged treatment. In addition to IGFBP-3 the bioavailability of IGF-1 can be modulated by using mesoporous silicon nanoparticles (NPs) which are optimal carriers for sustained release of unstable peptide hormones like IGF-1. In this study we compared biodistribution, pharmacokinetics, and bioavailability of radiolabeled free IGF-1, IGF1/IGFBP-3, and IGF-1/NP complexes in a Cln1-/- knockout mouse model. IGF-1/NP was mainly accumulated in liver and spleen in all studied time points, whereas minor and more constant amounts were measured in other organs compared to free IGF-1 or IGF-1/IGFBP-3. Also concentration of IGF-1/NP in blood was relatively high and stable during studied time points suggesting continuous release of IGF-1 from the particles.

\section{Introduction}

Infantile neuronal ceroid lipofuscinosis (INCL) is a severe neurodegenerative disorder of childhood characterized by selective death of cortical neurons [1]. Treatment is focused mainly to relieve the symptoms, such as sleep difficulties and epilepsy, but the average lifespan of an INCL child is still only 10 years. INCL is caused by recessive mutations in the CLN1 gene encoding palmitoyl-protein thioesterase (PPT1) [2]. Normal PPT1 activity is essential for the development and survival of cortical and cerebellar neurons in human and mouse [3-5]. IGF-1 concentration in cerebrospinal fluid is lower in patients with INCL [3] suggesting that decreased levels of IGF-1 in brain may accelerate neurodegenerative disorders. To consistently study pathogenesis and treatment of INCL and other types of neuronal ceroid lipofuscinoses (NCLs), different mouse models have been established (CLN1, CLN2, CLN3, CLN5) and also naturally occurring NCL mouse models exist (CLN8/mnd; CLN6/nclf) [6]. The Cln1-/- knockout mouse model is analogous to INCL in humans, with severe phenotype, and the overall neurologic features are highly similar to the clinical symptoms of INCL [4]. Furthermore, the analyses of two different $C \ln 1$-/- mouse models have revealed new pathological characteristics for INCL, including early thalamocortical neuron loss accompanied by astrocytosis, defects in axonal growth, cholesterol biosynthesis, and calcium metabolism [7-10].

Insulin-like growth factors, IGF-1 and IGF-2, are members of the insulin gene family and they play an important role in physiological development of humans and animals. 
IGF-1 and -2 stimulate cell proliferation and differentiation during embryonic and postnatal development. IGF-1 is the main trophic factor in the central nervous system (CNS) during early brain development $[11,12]$ and its relevance is greater to IGF-2. IGF-1 stimulates DNA synthesis, cell proliferation, neurite outgrowth, axonal growth, and myelination and enhances secretion of various neurotransmitters. IGF-1 signals many neurodegenerative diseases $[13,14]$ and lack of IGF-1 in the brain leads to apoptosis. IGF1 knockout mice show microcephaly and demyelination of the whole brain [15] and overstimulation of IGF-1 leads to macrocephaly [16]. In animal experiments neurotrophins have shown to have therapeutic effects on motor neuron disorder [17], chemotherapy-induced peripheral neuropathy [18], myelination and brain growth [19], asphyxia [20], cerebellar ataxia [21], retinopathy of prematurity [22], cognitive impairment [23], and experimental autoimmune encephalitis $[24,25]$. It has been shown that only oneweek treatment with IGF-1 partially restored interneuronal number and reduced hypertrophy in the $m n d / m n d$ mouse model of neuronal ceroid lipofuscinosis (CLN8) [26, 27].

IGF-1 is a polypeptide containing 70 amino acids, with a molecular weight of only $7.6 \mathrm{kDa}$. It is associated with one of the six known high-affinity binding proteins (IGFBP1 to 6). They have a central role in transporting IGFs in the bloodstream and cerebrospinal fluid and across the capillary barrier to the target cells [28] associating directly with cell membranes [29]. IGFBPs increase the half-time and stabilizing the IGF stimulation [30]. IGFBP-3 (MW $150 \mathrm{kDa}$ ) is the predominant IGFBP in serum. Most of the circulating IGF-1 and IGF-2 form a ternary complex with IGFBP-3 and acid labile subunit (ALS) [31].

Mesoporous silicon (PSi) micro- and nanoparticles are promising drug carriers for the targeted therapy for example, due to their high payload of therapeutic agents and biocompatibility $[32,33]$. Depending on the size and the surface chemistry of the pores increased or sustained release of the loaded therapeutic agents can be adjusted $[33,34]$. Porous silicon has already been utilized in the delivery of biologically unstable molecules such as peptides [35].

We have studied the biodistribution of I-125 labeled free IGF-1, IGF-1/IGFBP-3, and IGF-1/NP complexes in Cln1-/mouse model which genotypically and phenotypically represents INCL. Accumulation of free or complexed IGF1 in selected organs was measured at three time points. The aim of this study was to compare accumulation and pharmacokinetics of free and complexed IGF-1 to the brain in order to evaluate the therapeutic potential for INCL.

\section{Materials and Methods}

2.1. Radiolabeling. IGF-1 and IGFPB-3 were offered by Insmed Incorporation (Richmond, VA, USA). IGF-1 and IGFBP-3 were radiolabeled with ${ }^{125}$ I with Iodo-Gen method. Briefly, precoated iodination tubes (Pierce) were rinsed with $1 \mathrm{~mL}$ of phosphate-buffered saline, $\mathrm{pH} 7.4$, (PBS), and ${ }^{125} \mathrm{I}$ (22 MBq, Map Medicals, Finland) was incubated at room temperature for 10 minutes. After incubation IGF-1 $(200 \mu \mathrm{g})$ or IGFBP-3 $(200 \mu \mathrm{g})$ was added and the reaction mixture was further incubated for 15 minutes at RT. The solution was purified using HiTrap Sephadex column (GE Healthcare) using PBS as a mobile phase at flow rate $1 \mathrm{~mL} / \mathrm{min}$. Labeling efficiency was $29-43 \%$ with specific activity of $0.22 \mathrm{MBq} / \mathrm{nmol}$ and $0.37 \mathrm{MBq} / \mathrm{nmol}$ for the IGF- 1 and $11-$ $17 \%$ for the IGFBP-3 with specific activity of $0.29 \mathrm{MBq} / \mathrm{nmol}$ and $0.33 \mathrm{MBq} / \mathrm{nmol}$, respectively.

2.2. Nanoparticles. Thermally hydrocarbonized mesoporous silicon nanoparticles (THCPSi) were prepared as described earlier [36]. Nanoparticles $(800 \mu \mathrm{g})$ were mixed with radiolabelled IGF-1 $(200 \mu \mathrm{g})$ in $2 \mathrm{~mL}$ of $10 \mathrm{mM}$ HEPES $\mathrm{pH}$ 7.4. The suspension was mixed at RT for two hours sonicating every 30 minutes. $94 \%$ of IGF-1 was incorporated in the particles and the loading degree was $23.5 \%(\mathrm{w} / \mathrm{w})$. The in vitro release was studied using fresh mouse plasma diluted $1: 2$ in PBS. Nanoparticles were mixed with diluted plasma and incubated at $+37^{\circ} \mathrm{C}$. A sample of the particles was centrifuged immediately and at 20,60, 120, and 240 minutes time points ( $n=3 /$ time point). Radioactivity of the supernatant was measured by Gamma Counter (1277 Gammamaster automatic Gamma Counter, LKB Wallac, Finland).

2.3. Animals. A homozygous knockout mouse model Cln1-/-, showing overall neurologic features highly similar to the clinical symptoms of INCL, was used in this study [4]. The $C \ln 1-/-$ mice were backcrossed to $C 57 B L / 6$ for more than 10 generations, and the congeneity was confirmed with the Mouse Medium Density SNP Panel (Illumina). The genotypes of the mice were determined by PCR of DNA from tail biopsies. Total of 36 nine-week-old ( $n=3$ /group) female mice were used for the biodistribution studies. The mice received chow and water ad libitum. All animal procedures were performed according to protocols approved by the ethical boards for animal experimentation of the National Public Health Institute and University of Helsinki, as well as National Animal Experiment Board of Regional State Administrative Agencies of Southern Finland (Agreement number 09-06737), and all experiments were done in accordance with good practice of handling laboratory animals and genetically modified organisms.

2.4. Biodistribution Studies in Cln1-/- Mice. The biodistribution of radioiodinated IGF-1 was studied using free IGF-1, IGF-1 complexed with unlabeled IGFBP-3 (IGF1/IGFPB-3), or with nanoparticles (IGF-1/NP). In addition, the biodistribution of plain IGFBP-3 was studied. IGF-1 was complexed with IGFBP-3 using 2:1 molar ratio in PBS. The final protein concentration for the three protein preparations was $0.1 \mathrm{mg} / \mathrm{mL}$.

Animals were anesthetized by $1.5-2 \%$ isoflurane in $\mathrm{N}_{2} / \mathrm{O}_{2}$ with ratios $70: 30$, respectively. Labeled IGF-1, IGF1/IGFPB-3, IGF-1/NP, or IGFBP-3 was injected i.v. via tail vein using $10 \mu \mathrm{g}$ of IGF-1; 0.2-0.6 MBq/animal. Also $1 \mathrm{~mL}$ of $5 \%$ glucose was administrated i.p. to prevent hypoglycemia. Animals were sacrificed at 20, 120, or $240 \mathrm{~min}$ after injection. Tissue samples were collected in tared tubes 
TABle 1: Biodistribution of unbound IGF-1, IGF-1/IGFBP-3, IGFBP-3, and IGF1/NP complex 20 min, 120 min, and 240 min post-i.v. injection in CLN1-/- mice. The activity in all organs and tissue samples is expressed as percentage of injected dose/tissue sample weight $(\% \mathrm{ID} / \mathrm{g})$. All data are expressed as mean \pm standard error of the mean (S.E.M).

\begin{tabular}{|c|c|c|c|c|}
\hline \multirow{2}{*}{ Organ } & \multicolumn{4}{|c|}{ IGF-1 complex } \\
\hline & IGF-1 & IGF-1/IGFBP-3 & IGFBP-3 & IGF-1/NP \\
\hline \multicolumn{5}{|l|}{$20 \mathrm{~min}$} \\
\hline Blood & $10.21 \pm 0.92$ & $15.69 \pm 0.90$ & $12.24 \pm 0.49$ & $8.66 \pm 0.04$ \\
\hline Heart & $5.35 \pm 0.49$ & $7.70 \pm 0.23$ & $4.29 \pm 0.55$ & $2.45 \pm 0.06$ \\
\hline Lung & $11.37 \pm 1.00$ & $7.81 \pm 0.24$ & $10.30 \pm 1.95$ & $9.00 \pm 0.62$ \\
\hline Kidney & $148.3 \pm 34.48$ & $124.2 \pm 9.90$ & $34.98 \pm 8.90$ & $42.96 \pm 3.83$ \\
\hline Liver & $5.52 \pm 0.50$ & $50.06 \pm 2.21$ & $61.19 \pm 16.80$ & $56.45 \pm 8.44$ \\
\hline Spleen & $6.22 \pm 0.39$ & $28.37 \pm 1.22$ & $25.50 \pm 13.71$ & $47.15 \pm 4.11$ \\
\hline Ovary & $12.71 \pm 1.46$ & $4.22 \pm 0.57$ & $3.92 \pm 0.52$ & $3.09 \pm 0.45$ \\
\hline Muscle & $2.25 \pm 0.24$ & $0.77 \pm 0.05$ & $0.73 \pm 0.06$ & $0.85 \pm 0.00$ \\
\hline Brain & $0.60 \pm 0.04$ & $0.48 \pm 0.04$ & $0.42 \pm 0.00$ & $0.30 \pm 0.00$ \\
\hline \multicolumn{5}{|l|}{$120 \mathrm{~min}$} \\
\hline Blood & $8.01 \pm 0.92$ & $10.05 \pm 2.66$ & $15.82 \pm 2.01$ & $6.30 \pm 0.21$ \\
\hline Heart & $2.95 \pm 0.45$ & $3.76 \pm 1.22$ & $5.50 \pm 0.50$ & $1.71 \pm 0.08$ \\
\hline Lung & $6.57 \pm 0.97$ & $7.35 \pm 2.42$ & $9.49 \pm 1.06$ & $6.37 \pm 0.57$ \\
\hline Kidney & $14.32 \pm 2.23$ & $10.31 \pm 4.21$ & $12.40 \pm 1.19$ & $10.27 \pm 1.97$ \\
\hline Liver & $5.31 \pm 0.74$ & $7.95 \pm 4.78$ & $8.45 \pm 1.28$ & $17.75 \pm 0.83$ \\
\hline Spleen & $5.30 \pm 0.56$ & $9.45 \pm 3.28$ & $9.40 \pm 3.28$ & $14.71 \pm 2.49$ \\
\hline Ovary & $7.04 \pm 1.66$ & $7.78 \pm 2.14$ & $8.27 \pm 0.55$ & $2.99 \pm 0.11$ \\
\hline Muscle & $1.74 \pm 0.43$ & $1.75 \pm 0.48$ & $1.67 \pm 0.07$ & $0.91 \pm 0.03$ \\
\hline Brain & $0.35 \pm 0.08$ & $0.40 \pm 0.16$ & $0.51 \pm 0.04$ & $0.24 \pm 0.01$ \\
\hline \multicolumn{5}{|l|}{$240 \mathrm{~min}$} \\
\hline Blood & $5.71 \pm 0.41$ & $4.68 \pm 0.17$ & $6.24 \pm 0.43$ & $4.15 \pm 0.39$ \\
\hline Heart & $1.89 \pm 0.15$ & $1.46 \pm 0.08$ & $2.03 \pm 0.13$ & $1.00 \pm 0.12$ \\
\hline Lung & $4.10 \pm 0.46$ & $3.23 \pm 0.03$ & $3.93 \pm 0.46$ & $3.25 \pm 0.49$ \\
\hline Kidney & $4.20 \pm 0.25$ & $4.36 \pm 1.14$ & $3.87 \pm 0.31$ & $3.08 \pm 0.42$ \\
\hline Liver & $2.29 \pm 0.19$ & $1.79 \pm 0.17$ & $2.74 \pm 0.10$ & $11.29 \pm 0.63$ \\
\hline Spleen & $3.41 \pm 0.32$ & $3.16 \pm 0.38$ & $2.93 \pm 2.93$ & $9.05 \pm 1.01$ \\
\hline Ovary & $4.33 \pm 0.43$ & $3.49 \pm 0.16$ & $2.94 \pm 0.43$ & $1.47 \pm 0.03$ \\
\hline Muscle & $0.97 \pm 0.06$ & $0.90 \pm 0.14$ & $0.89 \pm 0.19$ & $0.54 \pm 0.03$ \\
\hline Brain & $0.20 \pm 0.01$ & $0.13 \pm 0.01$ & $0.19 \pm 0.01$ & $0.14 \pm 0.01$ \\
\hline
\end{tabular}

and radioactivity was measured using automated gamma counter (Clinigamma, Wallac, Finland). Corrections were made for background radiation and physical decay during counting. The activity in all organs and tissue samples was expressed as percentage of injected dose per gram $(\% \mathrm{ID} / \mathrm{g})$. All data were expressed as mean \pm standard error of the mean (S.E.M).

\section{Results}

Biodistribution of radiolabeled native IGF-1 was compared to IGF-1/IGFBP-3 and IGF-1/NP complexes and free IGFBP3 in $C \ln 1-/-$ mouse model. The animals were sacrificed 20, 120 , or $240 \mathrm{~min}$ after injection and radioactivity of selected organs was measured using a Gamma Counter (Table 1).

3.1. The In Vitro Release of IGF-1 from Nanoparticles. The release kinetics of IGF-1 from THCPSi nanoparticles was studied in vitro in mouse plasma at $+37^{\circ} \mathrm{C}$. As shown in Figure 1 there was a burst immediately after mixing with the plasma releasing $20 \%$ of the incorporated IGF- 1 . After 20 minutes half of the IGF- 1 was released and detachment rate was further decreased, $60 \%$ of IGF- 1 was uncoupled at 240 min time point.

3.2. Clearance and Bioavailability of the Native and Complexed IGF-1. As expected, most of the unbound IGF-1 was cleared through the kidneys within 120 minutes (Figure 2(a)). The clearance of IGF-1/IGFBP-3 through the kidneys was also high indicating fast dissociation since the labeled IGFBP3 was mainly excreted through the hepatic route. However, substantial part $(50.1 \% \mathrm{ID} / \mathrm{g})$ of IGF-1/IGFBP-3 was also eliminated through the liver after $20 \mathrm{~min}$. Excretion of IGF-1/NP via the kidneys was significantly inferior to unbound IGF-1 or IGF-1/IGFBP-3 (42.3\% ID/g; 148.3 and 


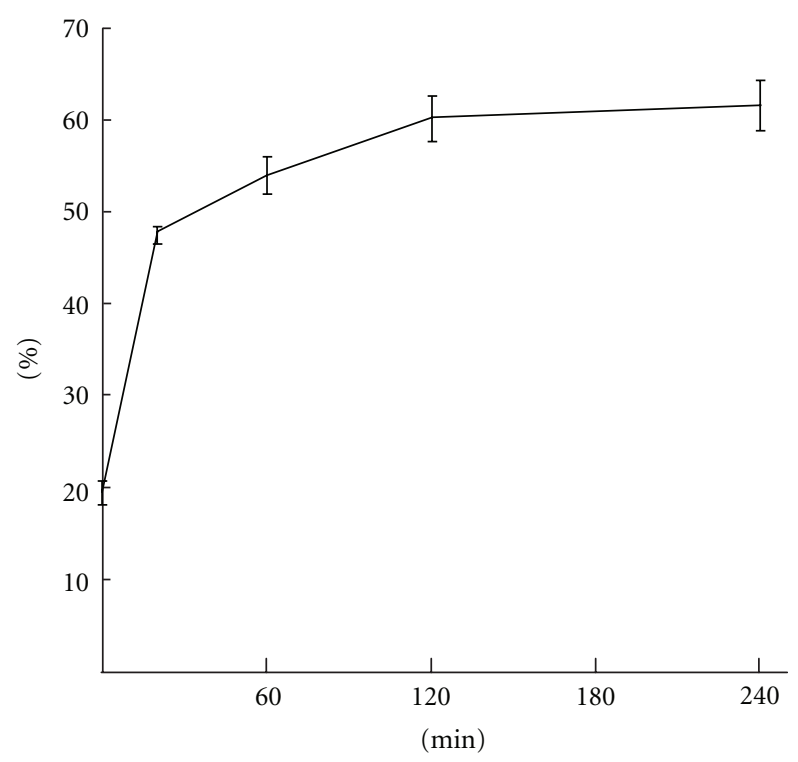

FIGURE 1: In vitro release of 125-I labelled IGF-1 from nanoparticles. $20 \%$ of the IGF- 1 was burst immediately after mixing with mouse plasma and $50 \%$ was released after 20 minutes incubation at $37^{\circ} \mathrm{C}$. Only $15 \%$ was released between 20 and 240 min time points.

$124.2 \% \mathrm{ID} / \mathrm{g}$ ) indicating sustained release of IGF-1 from the nanoparticles.

At 20 min time point accumulations of IGF-1/IGFBP-3 and IGF-1/NP in the liver were nearly equal $(50.1 \% \mathrm{ID} / \mathrm{g}$; $56.5 \% \mathrm{ID} / \mathrm{g})$. Interestingly, concentration of IGF-1/IGFBP3 in liver decreased to the level of IGF-1 between 20 and $120 \mathrm{~min}$ whereas the accumulation of IGF-1/NP was 2 times higher after $120 \mathrm{~min}$ and 5 times higher after 240 min than corresponding IGF-1/IGFBP-3 or protein alone (Figure 2(a)). Protein complexed IGF-1 was removed by active excretion whereas IFG-1/NP complex is concentrated into the liver and rather dissociated to the circulation than excreted immediately.

The level of IGF-1/IGFBP-3 in blood decreased faster in both time frames $20-120 \mathrm{~min}$ (36\%) and 120-240 min (53\%) than IGF-1/NP (Table 1). Concentration of IGF$1 / \mathrm{NP}$ in blood stayed steadier between both time frames (20-120 min, 27\%; 120-240 min, 34\%) like unbound IGF1 (Figure 1(b)). This suggests that IGF-1/NP is concentrated in liver and rather dissociated to circulation enabling longer bioavailability to other tissues than excreted immediately.

3.3. Brain. IGF-1 accumulated relatively low levels in the brain with or without complex in all studied time points (Figure 2(b)). The highest accumulation of IGF-1 was achieved at $20 \mathrm{~min}$ time point $(0.60 \% \mathrm{ID} / \mathrm{g})$ which was $25 \%$ more than IGF-1/IGFBP-3 (0.48\% ID/g) and twice as much as IGF-1/NP (0.30\% ID/g). However, accumulation of IGF-1 drops dramatically between 20-120 min (42\%), whereas levels of IGF-1/IFGBP-3 or IGF-1/NP decreased only $17 \%$ and $18 \%$, respectively, indicating more constant delivery of the IGF-1 in the brain. This data shows that the complexed forms of IGF-1 does not enhance delivery of IGF-1 in the brain but gives more stable concentrations. After 240 min IGF-1 accumulation in the brain was the same with or without complex.

3.4. Pharmacokinetics in Other Selected Tissues. Although the concentration of IGF-1/NP in blood was similar to the freely injected IGF-1 at all studied time points the accumulation of IGF-1/NP was lower than free IGF-1 and IGF-1/IGFBP3 in most of the studied organs, which may result in milder side effects. Pharmacokinetics of free IGF-1 and IGF-1/NP showed linear clearance during the first $240 \mathrm{~min}$ in all studied organs (Figure 2(b)), whereas the kinetics of IGF-1/IGFBP3 depended on the organ. In the ovaries and muscle the maximal activity was found at 120 minutes time point and at the remaining organs the highest accumulation was reached in $20 \mathrm{~min}$. Concentration of IGFBP-3 was highest at $120 \mathrm{~min}$ in all studied organs.

\section{Discussion}

The maturation of the $\mathrm{BBB}$ is species dependent. In some animals, the $\mathrm{BBB}$ matures during the earliest stages of gestation, while in others just before birth, and yet others not until after birth. In human infants, BBB maturation is complete approximately 6-12 months after birth [37, 38]. It is not known whether the BBB was already completed in the mice of the present study (at the age of 8-9 weeks of age). However, to be effective therapy, firstly, the drug should be given at an early age to prevent the damage and when BBB is still open. In animals, IGF-1 treatment strongly affects CNS myelination at an early age, but is ineffective later on, suggesting that there is critical period for CNS myelination [39]. Secondly, it must be noted that neurodegeneration and clinical course (maturation), are much faster in mice than in humans, for example, loss of vision occurs in mutant mouse at the age of 8 weeks and in humans at 8-18 months, respectively.

There is no direct evidence about the therapeutic effect of IGF-1 in mice. However, the effect of IGF-1 has been tested in several human disorders. Positive effects in adults have already been shown in body and brain growth [40-42], insulin resistance [43], and head injury [44]. In children it was used in growth hormone insensitivity syndrome (Laron syndrome). In adolescents with type 1 diabetes it has been used to promote insulin sensitivity. Recently, a study of IGF-1 as therapeutic agent in Rett syndrome have been initiated in Children's hospital, Boston (Khwaja, Clinical Trials.Gov ID NCT01253317). Also growth hormone treatment which has its main effect through IGF-1 has shown to be favorable to the motor and cognitive effects in CP [45].

The activity of free IGF-1 has been reported to be more active than IGF-1/IGFBP-3 [46]. However, undesired acute adverse reactions and the absence of suitable IGF-1 preparations for treatment have become major concerns among pediatric endocrinologists worldwide. The main problems in IGF-1 treatment include BBB permeability, side-effects like hypoglycemia, and short intervals in administration of the drug. IGF-1 complexed with binding protein 3 

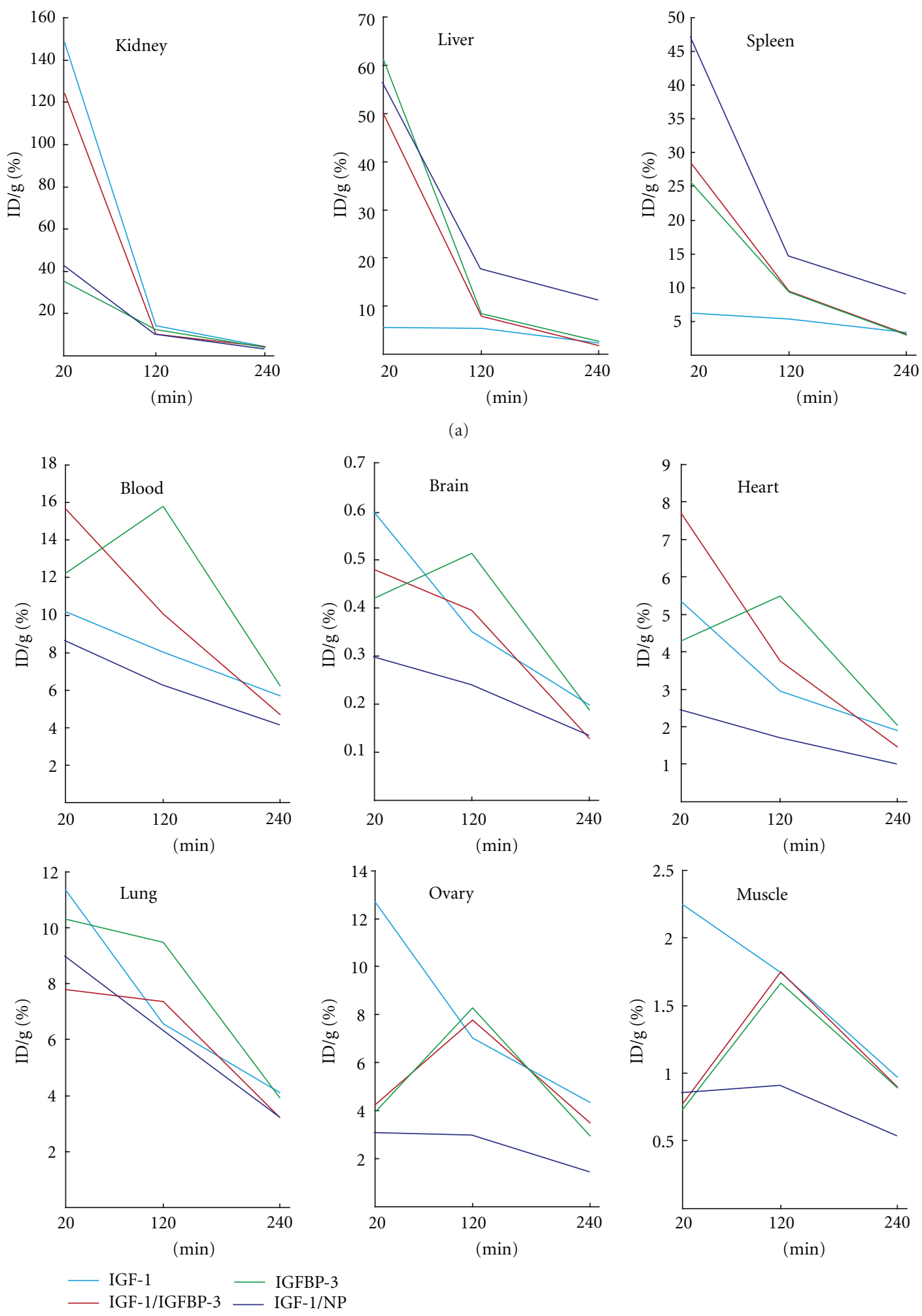

(b)

FIGURE 2: (a) Clearance of unbound and complexed IGF-1 in vivo. (b) Pharmacokinetics of free and complexed IGF-1 in selected organs. 
(Somatokine R) used in this study was developed to prolong the half-life and reducing side effects (including hypoglycemia). Recombinant hormone seems to be safe even in prolonged therapy for growth hormone insensitivity syndrome or for short children [47].

Our aim was to compare the biodistribution of free IGF1, IGF-1/IGFBP-3, and IGF-1/NP complex in selected organs over the time in Cln1-/- mouse model if IGF-1 could be used as a potential drug to treat INCL. It has been suspected that IGF-1/IGFBP-3 is too large to cross the BBB, but since IGF-1 is shed, it may eventually cross the BBB by specific transport systems [48, 49]. In Cln1-/- mice there is inflammation, and prominent alterations involved in the immune response $[4,9]$. Consequently, in the INCL patients, there might be inflammatory changes that could open BBB and the IGFs could cross it better than expected in healthy people.

Earlier studies in mice have shown that IGF-1 injected as such is bound to the plasma proteins immediately after the injection forming different size of complexes and is cleared via the kidneys $[50,51]$. In our biodistribution and pharmacokinetic studies iodinated IGF-1 was complexed to IGFBP-3 or nanoparticles in vitro before the injection. IGF-1 accumulated strongly in the liver only as a protein or nanoparticle complex. However, the protein complex was mainly excreted after two hours in contrast to IGF$1 / \mathrm{NP}$ which accumulation in liver was over $17 \% \mathrm{ID} / \mathrm{g}$ at the same time point. It has been shown that intravenously administered mesoporous silicon microparticles loaded with siRNA encapsulated into nanoliposomes accumulate into the liver and spleen, but remain in the sinusoidal space, enabling sustained release of siRNA-loaded nanoliposomes [52].

In our other studies we have analyzed behavior of I125 labeled thermally hydrocarbonized mesoporous silicon nanoparticles in liver using combined data of autoradiography and electron microscopy [53]. Similar nanoparticles as used in this study were seen in hepatic veins and sinusoids but not internalized into macrophages or hepatocytes. In addition, Bimbo et al. reported that THCPSi nanoparticles are not phagocytes in extent by CaCo-2 or RAW 264.7 macrophages in vitro. Instead they showed a strong cellular association as majority of the nanoparticles remained attached to cell membranes [54]. We suggest that IGF-1/NP is intact in the liver and IGF-1 may be released during the 240 min studied, whereas IGF-1/IGFBP-3 is cleared trough hepatic system. This can be seen as steadier IGF-1 release in blood compared IGF-1/NP to IGF-1/IGFBP-3 and is also in accordance with our in vitro results. More stable release of IGF-1 conjugated to NPs can be achieved as compared to protein complexes.

The doses used in our study have been the same as in experimental autoimmune encephalomyelitis mice where positive effects on inflammatory, demyelinating, and demyelinated lesions have been seen when using IGF-1 [55]. Relatively low levels of IGF-1 with or without IGFBP-3 or nanoparticles accumulated to the brains in all studied time points. The amount crossing the BBB might, however, be sufficient to affect the physiological functions and modulate neuroendocrine and behavioural responses. The sustained release to blood and low tissue concentrations of IFG-1 delivered with nanoparticles may decrease the side effects like hypoglycemia without losing the therapeutic effect. Low blood and tissue concentrations together with constant and sustained release may be beneficial for the continuous IGF-1 therapy for INCL.

In summary, we have studied the biodistribution and pharmacokinetics of human IGF-1 administrated free or complexed to its natural binding protein IGFBP-3 or nanoparticles in infantile neuronal ceroid lipofuscinosis (INCL) mouse model. IGF-1 conjugated to nanoparticles accumulated and also remained in liver probably in the hepatic veins and sinusoids at high concentration in contrast to IGF1/IGFPB-3 complex which dissociated and was actively excreted via kidneys and liver during studied time points. Since IGF-1/NP level also in blood decreased moderately compared to IGF-1/IGFBP-3 this data demonstrates steadier release of IGF-1 in to the circulation and longer bioavailability of IGF-1. Also IGF-1/NP concentration in all other studied tissues except spleen was lower than with protein complex or unbound IGF-1 which may result in milder side effects and is beneficial for the long-term hormone therapy.

\section{Acknowledgments}

IGF-1 and IGFBP-3 were provided by Insmed Incorporation. This work was partly supported by the Competitive research funding (EVO) of Kuopio University Hospital, Finland, and Finnish Academy (Grant no. 127138). The authors also want to thank D. Jarmo Jääskeläinen for his scientific comments of clinical use of IGF-1.

\section{References}

[1] P. Santavuori, "Neuronal ceroid-lipofuscinoses in childhood," Brain and Development, vol. 10, no. 2, pp. 80-83, 1988.

[2] J. Vesa, E. Hellsten, L. A. Verkruyse et al., "Mutations in the palmitoyl protein thioesterase gene causing infantile neuronal ceroid lipofuscinosis," Nature, vol. 376, no. 6541, pp. 584-587, 1995.

[3] R. Riikonen, S. L. Vanhanen, J. Tyynelä, P. Santavuori, and U. Turpeinen, "CSF insulin-like growth factor-1 in infantile neuronal ceroid lipofuscinosis," Neurology, vol. 54, no. 9, pp. 1828-1832, 2000.

[4] A. Jalanko, J. Vesa, T. Manninen et al., "Mice with $P p t 1^{\Delta e x 4}$ mutation replicate the INCL phenotype and show an inflammation-associated loss of interneurons," Neurobiology of Disease, vol. 18, no. 1, pp. 226-241, 2005.

[5] S. L. Macauley, D. F. Wozniak, C. Kielar, Y. Tan, J. D. Cooper, and M. S. Sands, "Cerebellar pathology and motor deficits in the palmitoyl protein thioesterase 1-deficient mouse," Experimental Neurology, vol. 217, no. 1, pp. 124-135, 2009.

[6] A. Jalanko and T. Braulke, "Neuronal ceroid lipofuscinoses," Biochimica et Biophysica Acta, vol. 1793, no. 4, pp. 697-709, 2009.

[7] L. Ahtiainen, J. Kolikova, A. L. Mutka et al., "Palmitoyl protein thioesterase 1 (Ppt1)-deficient mouse neurons show alterations in cholesterol metabolism and calcium homeostasis prior to synaptic dysfunction," Neurobiology of Disease, vol. 28, no. 1, pp. 52-64, 2007.

[8] L. Ahtiainen, K. Luiro, M. Kauppi, J. Tyynelä, O. Kopra, and A. Jalanko, "Palmitoyl protein thioesterase 1 (PPT1) 
deficiency causes endocytic defects connected to abnormal saposin processing," Experimental Cell Research, vol. 312, no. 9, pp. 1540-1553, 2006.

[9] C. von Schantz, J. Saharinen, O. Kopra et al., "Brain gene expression profiles of $\mathrm{Cln} 1$ and $\mathrm{Cln} 5$ deficient mice unravels common molecular pathways underlying neuronal degeneration in NCL diseases," BMC Genomics, vol. 9, article 146, 2008.

[10] C. Kielar, L. Maddox, E. Bible et al., "Successive neuron loss in the thalamus and cortex in a mouse model of infantile neuronal ceroid lipofuscinosis," Neurobiology of Disease, vol. 25, no. 1, pp. 150-162, 2007.

[11] I. Torres-Aleman, M. Villalba, and M. P. Nieto-Bona, "Insulinlike growth factor-I modulation of cerebellar cell populations is developmentally stage-dependent and mediated by specific intracellular pathways," Neuroscience, vol. 83, no. 2, pp. 321334, 1998.

[12] G. A. Werther, V. Russo, N. Baker, and G. Butler, "The role of the insulin-like growth factor system in the developing brain," Hormone Research, vol. 49, no. 1, supplement, pp. 37-40, 1998.

[13] J. L. Trejo, E. Carro, E. Garcia-Galloway, and I. TorresAleman, "Role of insulin-like growth factor I signaling in neurodegenerative diseases," Journal of Molecular Medicine, vol. 82, no. 3, pp. 156-162, 2004.

[14] R. Riikonen, "Neurotrophic factors in the pathogenesis of neurological disorders with mental retardation in children," Current Pediatric Reviews, vol. 3, no. 3, pp. 207-213, 2007.

[15] K. D. Beck, L. Powell-Braxton, H. R. Widmer, J. Valverde, and F. Hefti, "Igfl gene disruption results in reduced brain size, CNS hypomyelination, and loss of hippocampal granule and striatal parvalbumin-containing neurons," Neuron, vol. 14, no. 4, pp. 717-730, 1995.

[16] E. J. Schoenle, G. K. Haselbacher, and J. Briner, "Elevated concentration of IGF II in brain tissue from an infant with macrencephaly," Journal of Pediatrics, vol. 108, no. 5, pp. 737$740,1986$.

[17] J. Zhong, L. Zhao, Y. Du, G. Wei, W. G. Yao, and W. H. Lee, "Delayed IGF-1 treatment reduced long-term hypoxiaischemia-induced brain damage and improved behavior recovery of immature rats," Neurological Research, vol. 31, no. 5, pp. 483-489, 2009.

[18] S. C. Apfel, J. C. Arezzo, M. E. Lewis, and J. A. Kessler, "The use of insulin-like growth factor I in the prevention of vincristine neuropathy in mice," Annals of the New York Academy of Sciences, vol. 692, pp. 243-245, 1993.

[19] M. J. Carson, R. R. Behringer, R. L. Brinster, and F. A. McMorris, "Insulin-like growth factor I increases brain growth and central nervous system myelination in transgenic mice," Neuron, vol. 10, no. 4, pp. 729-740, 1993.

[20] J. Guan, "Insulin-like growth factor-1 and its derivatives: potential pharmaceutical application for ischemic brain injury," Recent Patents on CNS Drug Discovery, vol. 3, no. 2, pp. 112-127, 2008.

[21] A. M. Fernandez, A. Gonzalez De La Vega, and I. TorresAleman, "Insulin-like growth factor I restores motor coordination in a rat model of cerebellar ataxia," Proceedings of the National Academy of Sciences of the United States of America, vol. 95, no. 3, pp. 1253-1258, 1998.

[22] A. Hellstrom, C. Perruzzi, M. Ju et al., "Low IGF-I suppresses VEGF-survival signaling in retinal endothelial cells: direct correlation with clinical retinopathy of prematurity," Proceedings of the National Academy of Sciences of the United States of America, vol. 98, no. 10, pp. 5804-5808, 2001.

[23] S. B. Lupien, E. J. Bluhm, and D. N. Ishii, "Systemic insulin-like growth factor-I administration prevents cognitive impairment in diabetic rats, and brain IGF regulates learning/memory in normal adult rats," Journal of Neuroscience Research, vol. 74, no. 4, pp. 512-523, 2003.

[24] A. E. Lovett-Racke, P. Bittner, A. H. Cross, J. A. Carlino, and M. K. Racke, "Regulation of experimental autoimmune encephalomyelitis with insulin-like growth factor (IGF-1) and IGF1/IGF-binding protein-3 complex (IGF-1/IGFBP3)," Journal of Clinical Investigation, vol. 101, no. 8, pp. 1797-1804, 1998.

[25] D. L. Yao, X. Liu, L. D. Hudson, and H. D. F. Webster, "Insulinlike growth factor-I given subcutaneously reduces clinical deficits, decreases lesion severity and upregulates synthesis of myelin proteins in experimental autoimmune encephalomyelitis," Life Sciences, vol. 58, no. 16, pp. 1301-1306, 1996.

[26] J. D. Cooper, A. Messer, J. Chua-Couzens, and W. C. Mobley, "Apparent loss and hypertrophy of interneurons in a mouse model of neuronal ceroid lipofuscinosis: evidence for partial response to insulin- like growth factor-1 treatment," Journal of Neuroscience, vol. 19, no. 7, pp. 2556-2567, 1999.

[27] S. Ranta, Y. Zhang, B. Ross et al., "The neuronal ceroid lipofuscinoses in human EPMR and mnd mutant mice are associated with mutations in CLN8," Nature Genetics, vol. 23, no. 2, pp. 233-236, 1999.

[28] R. C. Baxter, "Insulin-like growth factor binding proteins in the human circulation: a review," Hormone Research, vol. 42, no. 4-5, pp. 140-144, 1994.

[29] C. A. Conover, M. Ronk, F. Lombana, and D. R. Powell, "Structural and biological characterization of bovine insulinlike growth factor binding protein-3," Endocrinology, vol. 127, no. 6, pp. 2795-2803, 1990.

[30] R. Rajah, A. Khare, P. D. K. Lee, and P. Cohen, "Insulin-like growth factor-binding protein-3 is partially responsible for high-serum-induced apoptosis in PC-3 prostate cancer cells," Journal of Endocrinology, vol. 163, no. 3, pp. 487-494, 1999.

[31] J. Dupont and M. Holzenberger, "Biology of insulin-like growth factors in development," Birth Defects Research Part C, vol. 69, no. 4, pp. 257-271, 2003.

[32] S. C. Bayliss, R. Heald, D. I. Fletcher, and L. D. Buckberry, "The culture of mammalian cells on nanostructured silicon," Advanced Materials, vol. 11, pp. 318-321, 1999.

[33] J. Salonen, A. M. Kaukonen, J. Hirvonen, and V. P. Lehto, "Mesoporous silicon in drug delivery applications," Journal of Pharmaceutical Sciences, vol. 97, no. 2, pp. 632-653, 2008.

[34] T. Limnell, J. Riikonen, J. Salonen et al., "Surface chemistry and pore size affect carrier properties of mesoporous silicon microparticles," International Journal of Pharmaceutics, vol. 343, no. 1-2, pp. 141-147, 2007.

[35] M. Kilpeläinen, J. Mönkäre, M. A. Vlasova et al., "Nanostructured porous silicon microparticles enable sustained peptide (Melanotan II) delivery," European Journal of Pharmaceutics and Biopharmaceutics, vol. 77, no. 1, pp. 20-25, 2011.

[36] J. Salonen, M. Björkqvist, E. Laine, and L. Niinistö, "Stabilization of porous silicon surface by thermal decomposition of acetylene," Applied Surface Science, vol. 225, no. 1-4, pp. 389394, 2004.

[37] F. Joo, "Current aspects of the development of the blood-brain barrier," International Journal of Developmental Neuroscience, vol. 5, no. 5-6, pp. 369-372, 1987.

[38] N. R. Saunders, G. W. Knott, and K. M. Dziegielewska, "Barriers in the immature brain," Cellular and Molecular Neurobiology, vol. 20, no. 1, pp. 29-40, 2000.

[39] R. C. Wiggins, "Myelin development and nutritional insufficiency.," Brain Research, vol. 257, no. 2, pp. 151-175, 1982.

[40] Z. Laron, S. Anin, Y. Klipper-Aurbach, and B. Klinger, "Effects of insulin-like growth factor on linear growth, head 
circumference, and body fat in patients with Laron-type dwarfism," The Lancet, vol. 339, no. 8804, pp. 1258-1261, 1992.

[41] Z. Laron, "The essential role of IGF-I: lessons from the longterm study and treatment of children and adults with Laron syndrome," Journal of Clinical Endocrinology and Metabolism, vol. 84, no. 12, pp. 4397-4404, 1999.

[42] Z. Laron, "Insulin-like growth factor-I (IGF-I): safety and efficacy," Pediatric Endocrinology Reviews, vol. 2, no. 1, pp. 78 85, 2004.

[43] H. Vestergaard, M. Rossen, S. A. Urhammer, J. Müller, and O. Pedersen, "Short- and long-term metabolic effects of recombinant human IGF-I treatment in patients with severe insulin resistance and diabetes mellitus," European Journal of Endocrinology, vol. 136, no. 5, pp. 475-482, 1997.

[44] J. Hatton, R. P. Rapp, K. A. Kudsk et al., "Intravenous insulin-like growth factor-I (IGF-I) in moderate-to-severe head injury: a phase II safety and efficacy trial," Journal of Neurosurgery, vol. 86, no. 5, pp. 779-786, 1997.

[45] W. Pan and A. J. Kastin, "Interactions of IGF-1 with the bloodbrain barrier in vivo and in situ," Neuroendocrinology, vol. 72, no. 3, pp. 171-178, 2000.

[46] Z. Laron, "Insulin-like growth factor-I treatment of children with Laron syndrome (primary growth hormone insensitivity)," Pediatric Endocrinology Reviews, vol. 5, no. 3, pp. 766771, 2008.

[47] L. K. Midyett, A. D. Rogol, Q. L. Van Meter, J. Frane, and G. M. Bright, "Recombinant insulin-like growth factor (IGF)-I treatment in short children with low IGF-I levels: first-year results from a randomized clinical trial," Journal of Clinical Endocrinology and Metabolism, vol. 95, no. 2, pp. 611-619, 2010.

[48] J. Devesa, N. Casteleiro, C. Rodicio, N. López, and P. Reimunde, "Growth hormone deficiency and cerebral palsy," Journal of Therapeutics and Clinical Risk Management, vol. 6, pp. 413-418, 2010.

[49] Y. Yu, A. J. Kastin, and W. Pan, "Reciprocal interactions of insulin and insulin-like growth factor I in receptor-mediated transport across the blood-brain barrier," Endocrinology, vol. 147, no. 6, pp. 2611-2615, 2006.

[50] B. F. Sun, H. Kobayashi, N. Le et al., "Effects of insulinlike growth factor binding proteins on insulinlike growth factorI biodistribution in tumor-bearing nude mice," Journal of Nuclear Medicine, vol. 41, no. 2, pp. 318-326, 2000.

[51] B. F. Sun, H. Kobayashi, N. Le et al., "Biodistribution of 125Ilabeled des(1-3) insulin-like growth factor I in tumor-bearing nude mice and its in vitro catabolism," Cancer Research, vol. 57, no. 13, pp. 2754-2759, 1997.

[52] T. Tanaka, L. S. Mangala, P. E. Vivas-Mejia et al., "Sustained small interfering RNA delivery by mesoporous silicon particles," Cancer Research, vol. 70, no. 9, pp. 3687-3696, 2010.

[53] J. Rytkönen, R. Miettinen, M. Kasalainen, V.-P. Lehto, J. Salonen, and A. Närvänen, "Functionalization of mesoporous silicon nanoparticles for targeting and bioimaging purposes," Journal of Nanomaterials, In press.

[54] L. M. Bimbo, M. Sarparanta, H. A. Santos et al., "Biocompatibility of thermally hydrocarbonized porous silicon nanoparticles and their biodistribution in rats," ACS Nano, vol. 4, no. 6, pp. 3023-3032, 2010.

[55] W. Li, L. Quigley, D. L. Yao et al., "Chronic relapsing experimental autoimmune encephalomyelitis: effects of insulin-like growth factor-I treatment on clinical deficits, lesion severity, glial responses, and blood brain barrier defects," Journal of Neuropathology and Experimental Neurology, vol. 57, no. 5, pp. 426-438, 1998. 

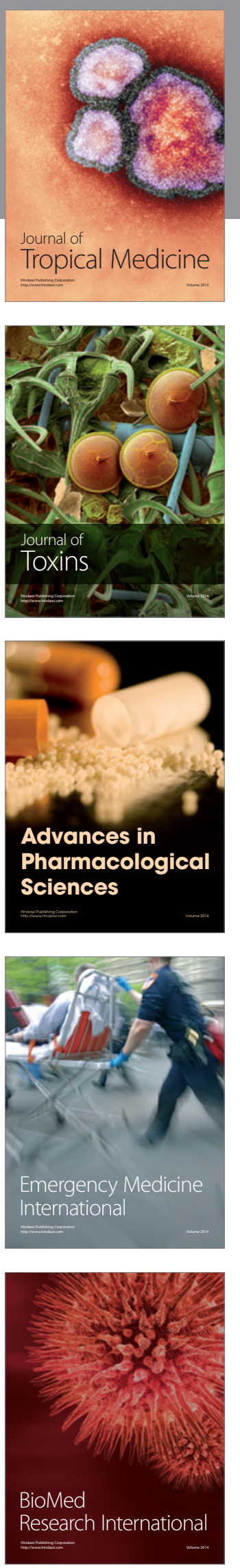
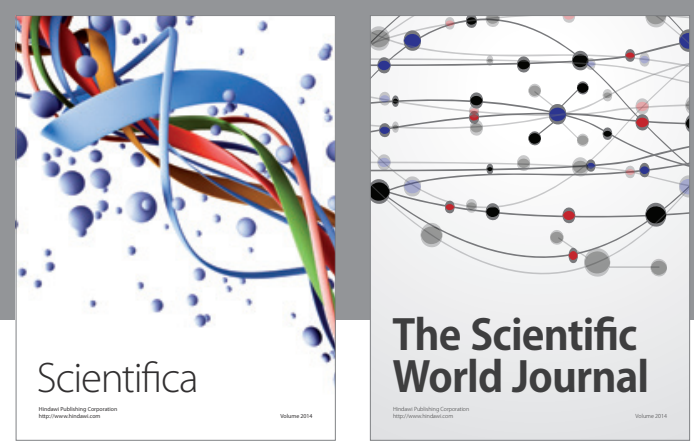

The Scientific World Journal
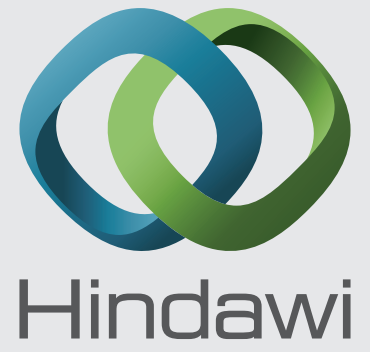

Submit your manuscripts at

http://www.hindawi.com
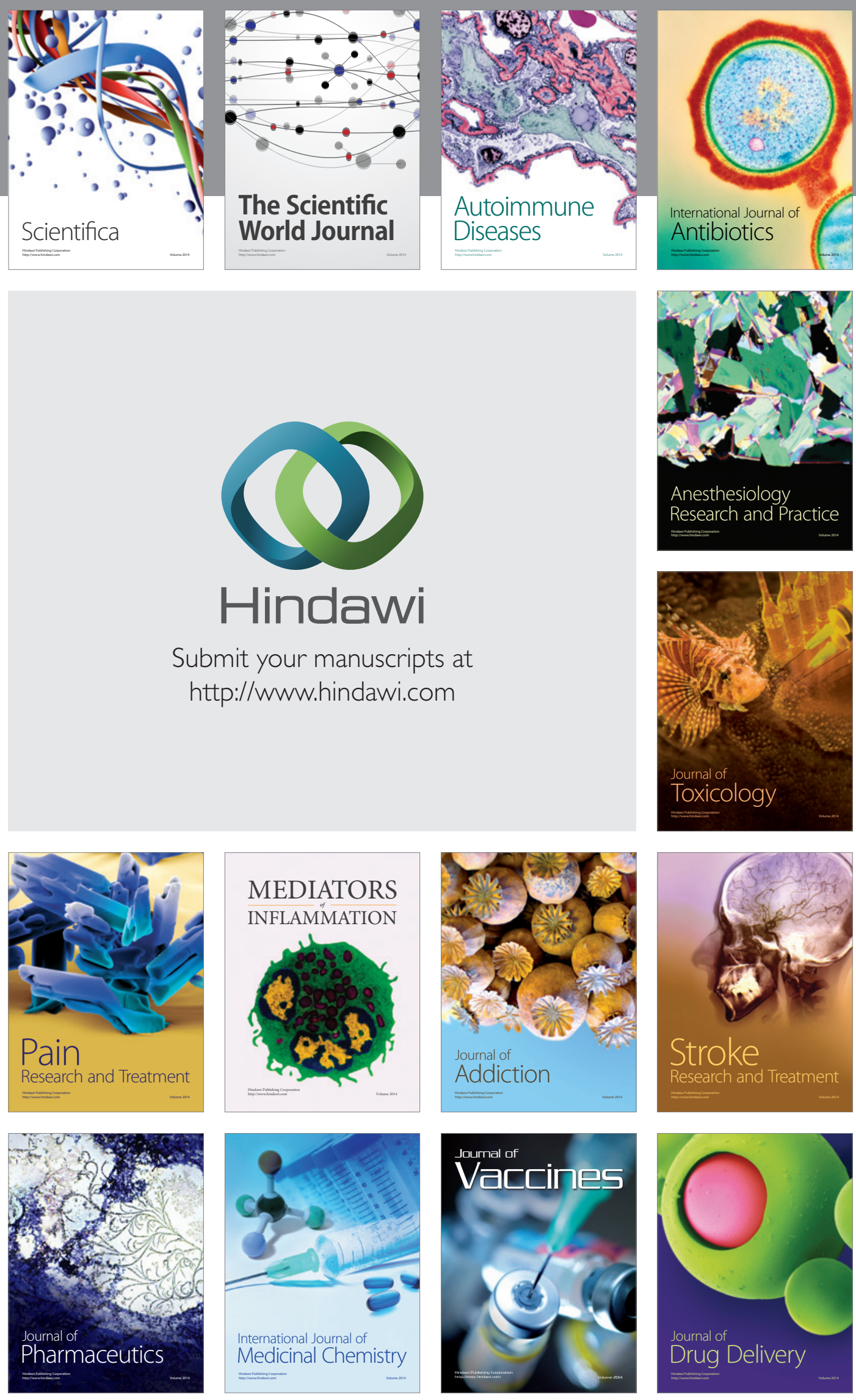